\title{
LITERASI ICT DALAM KALANGAN PELAJAR SARJANA MUDA
}

\section{ICT LITERACY AMONG UNDERGRADUATE STUDENTS}

\author{
Wan Hussain Wan Ishak ${ }^{1}$ \\ Pusat Pengajian Pengkomputeran, Universiti Utara Malaysia (UUM), Malaysia. \\ (Email: hussain@uum.edu.my) \\ Fadhilah Mat Yamin ${ }^{2}$ \\ Pusat Pengajian Pengurusan Teknologi dan Logistik, Universiti Utara Malaysia (UUM), Malaysia. \\ (Email: fmy@uum.edu.my)
}

Received date: 09-05-2019

Revised date: 24-07-2019

Accepted date: $28-07-2019$

Published date: 12-09-2019

To cite this document: Ishak, W. H. W., \& Mat Yamin, F. (2019). Literasi ICT dalam Kalangan Pelajar Sarjana Muda. International Journal of Education, Psychology and Counseling, 4 (32), 43-50.

DOI: $10.35631 /$ IJEPC.432005

\begin{abstract}
Abstrak: Literasi ICT atau kemahiran menggunakan teknologi maklumat dan komunikasi (ICT) dalam kalangan pelajar merupakan salah satu aspek penting dalam pendidikan masa kini. Ini kerana pada masa kini, ICT merupakan salah satu pemangkin utama kemajuan sesebuah negara. Revolusi industri 4.0 misalnya, menekankan pengunaan ICT dalam setiap aspek operasi organisasi. Organisasi yang tidak menggunakan ICT akan ketinggalan dan lemah daya saing mereka berbanding organisasi lain. Selaras dengan itu, pihak industri memerlukan pelajar yang berkemahiran tinggi bagi membolehkan mereka maju kehadapan seiring dengan pesaing mereka. Sehubungan itu, kajian telah dijalankan ke atas sekumpulan pelajar bagi mengukur tahap literasi ICT mereka. Secara keseluruhannya, tahap literasi semasa pelajar adalah baik terutama dalam aspek penggunaan perisian aplikasi. Walau bagaimanapun aspek pengetahuan teknikal seperti memasang dan menggunakan peralatan ICT, tahap literasi pelajar adalah sederhana. Dapatan ini menunjukkan pelajar masih perlu meningkatkan tahap literasi ICT mereka melalui latihan dan amalan ICT yang konsisten sepanjang pengajian mereka di universiti.
\end{abstract}

Kata Kunci: ICT, Literasi ICT, Penggunaan ICT, Kemahiran ICT

Abstract: ICT literacy or the use of information and communication technology (ICT) skills among students is an important aspect of today's education. This is because at present, ICT is one of the major catalysts of a nation's development. The industrial revolution of 4.0, for example, emphasizes the use of ICT in every aspect of organizational operations. Organizations that do not utilize ICT will be left behind and lack of competitive power compared to other organizations. In line with that, the industry requires highly skilled students to enable them to move forward in tandem with their competitors. In this regard, a study was conducted on a group of students to measure their ICT literacy level. Overall, the level of 
current literacy of students is good, especially in the aspect of application software. However, aspects of technical knowledge such as installing and using ICT equipment, the level of student literacy is modest. This finding shows that students still need to increase their ICT literacy level through consistent ICT training and practice throughout their studies at the university.

Keywords: ICT, ICT Literacy, ICT Usage, ICT Skill

\section{Pengenalan}

Teknologi Maklumat dan Komunikasi atau ICT (Information Communication and Technology) merupakan salah satu teknologi utama dalam pembangunan negara. Pada masa kini, semua organisasi samada kerajaan atau swasta, kecil atau besar, bertaraf kebangsaan atau antarabangsa, menjadikan ICT sebagai salah satu aset utama mereka. Ini kerana ICT boleh digunakan pada pelbagai peringkat dalam organisasi. Malah penggunaan ICT memberi banyak kelebihan seperti; mengurangkan kos, meningkatkan kecekapan organisasi, meningkatkan kecekapan pembuatan keputusan dan meningkatkan daya saing organisasi di pasaran (Linton, 2018; Palvalin, et al., 2013). Sebaliknya, kelemahan penguasaan ICT dalam organisasi akan mengurangkan keberkesanan penggunaan ICT (Plaatjies \& Mitrovic, 2014) dan melemahkan daya saing organisasi.

Sejak penubuhan Koridor Raya Multimedia (MSC) pada tahun 1996, penggunaan ICT dalam kalangan masyarakat dan perniagaan telah meningkat. Malah MSC memberi kesan positif ke atas ekonomi Malaysia (Ramlan \& Ahmed, 2010). Suruhanjaya Komunikasi dan Multimedia Malaysia (SKMM) telah melaporkan purata penggunaan dan capaian ICT oleh individu dan isi rumah di Malaysia pada tahun 2015 adalah sebanyak 67.6\% (SKMM, 2016). Manakala dalam kalangan industri, penggunaan ICT boleh dilihat melalui status MSC Malaysia yang dianugerahkan oleh kerajaaan melalui Malaysia Digital Economy Corporation Sdn Bhd (MDEC). Status ini melambangkan pengikirafan kerajaan Malaysia terhadap amalan dan penggunaan teknologi ICT dalam pelbagai aspek operasi organisasi seperti pengurusan dan peningkatan pengeluaran produk dan perkhidmatan. Menurut MDEC (2016) sehingga tahun 2015, lebih 3,800 buah syarikat telah dianugerahkan status MSC Malaysia dimana sebanyak 132 organisasi adalah institusi pendidikan tinggi (IPT) dan inkubator.

Revolusi industri 4.0 memberi lebih tekanan kepada organisasi untuk meningkatkan implementasi ICT dalam operasi mereka. Ini kerana industri 4.0 menekankan penggunaan teknologi tinggi dalam operasi dan pengeluaran seperti Internet of Thing (IoT), kepintaran buatan, robot, sensor dan sebagainya (Bonner, 2017). Asas kepada penguasaan teknologi ini adalah pengetahuan dan kemahiran ICT.

Pengetahuan dan kemahiran ICT merupakan antara pengetahuan asas yang diperolehi sepanjang graduan menuntut di institusi pengajian tinggi. Walau bagaimanapun, tahap pengetahuan pelajar sukar ditentukan kerana tidak semua pengetahuan ICT diperolehi secara langsung. Kebanyakkan kemahiran ICT telah dibenam dalam silibus pengajaran dan pelajar diharapkan akan dapat mengaplikasikan kemahiran ICT bersesuaian dengan keperluan kursus mereka. Pelajar juga didedahkan dengan teknologi ICT baharu dan mereka digalakkan untuk mencuba teknologi berkenaan. Secara tidak langsung kemahiran ICT pelajar akan dipertingkatkan. Oleh itu, kajian telah dilaksanakan bagi meninjau tahap literasi ICT dalam kalangan pelajar. 
Kertas kerja ini membincangkan hasil tinjauan yang dilakukan ke atas pelajar sarjana muda bagi mengukur tahap literasi ICT mereka. Literasi ICT pelajar amat penting kerana tanpa pengetahuan ICT, kemahiran penggunaan ICT juga turut lemah.

\section{Keperluan Terhadap Literasi ICT}

Pelajar yang mempunyai kemahiran ICT yang mencukupi dijangka akan mampu menggunakan pelbagai sumber yang ada seperti perkakasan komputer, rangkaian komputer, perisian dan internet bagi memenuhi keperluan maklumat mereka. Melalui perkakasan, alatan dan perisian yang ada, pelajar boleh mencari pelbagai maklumat, menapis dan membuat analisis yang diperlukan (Yamin \& Ishak, 2016). Penguasaan kemahiran ICT di peringkat universiti akan membantu memudahkan pelajar masuk dan bersaing di pasaran kerja. Ini kerana organisasi memerlukan kakitangan yang mampu menggunakan ICT dengan baik.

Pengetahuan ICT mencakupi pelbagai kemahiran dalam penggunaan alatan ICT seperti menggunakan alatan dan perkakasan komputer, perisian aplikasi, internet dan sebagainya. Kebolehan menggunakan teknologi ini secara berkesan dilihat sebagai prasyarat untuk memenuhi pasaran kerja pada hari ini. Penyelidikan terdahulu menunjukkan bahawa penggunaan ICT membawa kepada prestasi akademik yang lebih baik (Hoskins dan van Hooff, 2005; Hernandez, 2017; Basri et al., 2018). Pencapaian ini secara tidak langsung akan meningkatkan prospek pelajar dalam pasaran buruh.

Malah, penstrukturan semula yang berlaku dalam kebanyakkan organisasi perniagaan telah memperlihatkan ICT sebagai salah satu komponen utama dalam organisasi. Ichniowski et al., (1997) mendapati terdapat kesan positif dalam organisasi apabila teknologi ICT diaplikasikan. Oleh itu, kemahiran ICT dalam kalangan pekerja amat diperlukan dalam organisasi. individu yang lemah kemahiran ICT akan ketinggalan dan tidak mampu bersaing dalam pasaran kerja (Tyler, 2005).

\section{Kaedah Kajian}

Sejumlah 61 orang pelajar sarjana muda tahun akhir yang sedang mengikuti pelbagai program akademik di Universiti Utara Malaysia telah dipilih secara rawak sebagai responden. Mereka diberi soalan soal selidik dengan skala likert dari 1 hingga 5. Skala ini mewakili tahap kecekapan pelajar dalam empat aspek ICT iaitu isu dan operasi asas komputer, perisian aplikasi, penggunaan internet, dan peralatan ICT. Soalan kaji selidik ini di terima pakai dari Yusuf \& Balogun (2011). Jadual 1 menunjukkan penerangan bagi skala yang digunakan.

Table 1: Penerangan Bagi Skala Likert

\begin{tabular}{|c|l|l|}
\hline Skala & Kod & Penerangan \\
\hline 1 & NA & "I am not aware of this application/operation" \\
\hline 2 & DU & "I do not use" \\
\hline 3 & OU & "I have used this occasionally but need further training" \\
\hline 4 & RCU & "I am a regular and confident user of this application" \\
\hline 5 & FC & "I am fully competent with this application/operation" \\
\hline
\end{tabular}

Analisis deskriptif telah dijalankan ke atas maklum balas pelajar bagi melihat maklum balas pelajar terhadap setiap soalan yang dikemukakan. Maklum balas pelajar dipermudahkan dengan mengabungkan skala 1 hingga 5 kepada 3 kelas iaitu; rendah, pertengahan dan tinggi. Skala 1 dan 2 dikelaskan sebagai rendah, skala 3 sebagai pertengahan dan skala 4 dan 5 dikelaskan sebagai tinggi. 


\section{Dapatan Kajian}

Rajah 1 menunjukkan taburan pelajar yang terlibat mengikut jantina. Seperti yang ditunjukkan dalam Rajah 1, kebanyakkan responden adalah perempuan (83\%), manakala lelaki hanya $17 \%$ sahaja.

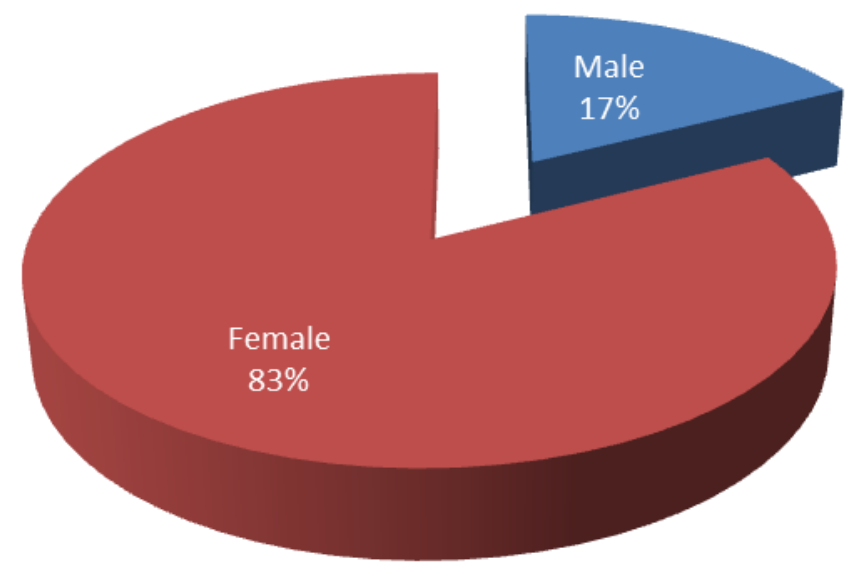

Rajah 1: Jantina

Jadual 2 menunjukkan maklum balas pelajar terhadap isu dan operasi asas komputer. Maklum balas menunjukkan pelajar sudah biasa dengan kebanyakkan operasi asas komputer seperti membuka perisian aplikasi, mencari fail, menggunakan CD/DVD, menggunakan folder, menukar pemacu dan membuat cetakan. Walau bagaimanapun, sebahagian pelajar (kurang dari 50\%) jarang menggunakan peranti persisian komputer. Keadaan ini mungkin berpunca dari pelajar jarang memasang dan menanggalkan peranti komputer mereka. Pelajar juga didapati kurang perihatin mengenai isu keselamatan dan kesihatan yang berkait dengan penggunaan komputer Seperti yang ditunjukkan dalam Jadual 1, kurang 40\% pelajar perihatin dengan isu keselamatan komputer dan kesihatan pengguna.

Jadual 2: Isu dan Asas Operasi Komputer

\begin{tabular}{|l|c|c|c|}
\hline & $\begin{array}{c}\text { Rendah } \\
(\%)\end{array}$ & $\begin{array}{c}\text { Pertengahan } \\
(\%)\end{array}$ & $\begin{array}{c}\text { Tinggi } \\
(\%)\end{array}$ \\
\hline $\begin{array}{l}\text { CO_1: I can locate and run an application program } \\
\text { e.g. word. }\end{array}$ & 7.94 & 22.22 & 69.84 \\
\hline CO_2: I can search for files on computer system. & 0.00 & 14.29 & 85.71 \\
\hline $\begin{array}{l}\text { CO_3: I can connect the computer and its } \\
\text { peripherals. }\end{array}$ & 6.35 & 39.68 & 53.97 \\
\hline CO_4: I can access information on CD/DVD. & 3.17 & 19.05 & 77.78 \\
\hline CO_5: I can organize electronic files into folders. & 7.94 & 15.87 & 76.19 \\
\hline $\begin{array}{l}\text { CO_6: I can move files between drives (e.g. from A: } \\
\text { to C). }\end{array}$ & 4.76 & 7.94 & 87.30 \\
\hline C0_7: I can print to various networked printers. & 0.00 & 34.92 & 65.08 \\
\hline $\begin{array}{l}\text { C0_8: I am aware of computer security, copyright } \\
\text { and the law. }\end{array}$ & 6.35 & 55.56 & 38.10 \\
\hline $\begin{array}{l}\text { CO_9: I am aware of health and safety issues relating } \\
\text { to the computing environment. }\end{array}$ & 14.29 & 49.21 & 36.51 \\
\hline
\end{tabular}

Jadual 3-pula menunjukkan maklumbalas pelajar terhadap penggunaan perisian aplikasi. Dalam kajian ini responden diminta memberi maklumbalas terhadap tiga perisian aplikasi yang 
lazim mereka gunakan iaitu Microsoft Word, Microsoft Excel dan Microsoft PowerPoint. Seperti yang telah dijangka, pelajar sememangnya arif menggunakan perisian Microsoft Word. Lebih $90 \%$ responden tahu mencipta dokumen baharu dan tahu menggunakan fungsian asas dalam Microsoft Word. Responden juga tahu menggunakan perisian Microsoft PowerPoint bagi menghasilkan slide pembentangan. Hasil maklum balas responden menunjukkan lebih $70 \%$ responden tahu mencipta slide pembentangan dan mengemaskini warna dan tulisan. Malah lebih $60 \%$ responden tahu menggunakan animasi dalam slide pembentangan mereka. Penguasaan pelajar terhadap perisian Microsoft Excel agak rendah berbanding perisian Microsoft Word dan PowerPoint. Maklum balas menunjukkan kurang 50\% responden tahu menggunakan Microsoft Excel dengan baik, membuat ramalan dan menyusun serta menapis data. Dapatan ini menunjukkan bahawa perisian Microsoft Excel agak teknikal dalam kalangan pelajar. Oleh itu tidak semua pelajar dapat menguasainya dengan baik.

Jadual 3: Perisian Aplikasi

\begin{tabular}{|l|c|c|c|}
\hline & $\begin{array}{c}\text { Rendah } \\
(\%)\end{array}$ & $\begin{array}{c}\text { Pertengahan } \\
(\%)\end{array}$ & $\begin{array}{c}\text { Tinggi } \\
(\%)\end{array}$ \\
\hline AS_1: I can open a new document in word. & 0.00 & 4.76 & 95.24 \\
\hline $\begin{array}{l}\text { AS_2: I can use simple editing e.g. bold, italics, } \\
\text { centering, font size, etc. }\end{array}$ & 0.00 & 4.76 & 95.24 \\
\hline AS_3: I can use spreadsheet package very well. & 7.94 & 47.62 & 44.44 \\
\hline AS_4: I can use spreadsheet to make predictions. & 12.70 & 47.62 & 39.68 \\
\hline AS_5: I can sort and filter data. & 9.52 & 42.86 & 47.62 \\
\hline AS_6: I can create a basic presentation package. & 3.17 & 20.63 & 76.19 \\
\hline $\begin{array}{l}\text { AS_7: I can modify colors of text, lines and spaces } \\
\text { on a slide. }\end{array}$ & 0.00 & 12.70 & 87.30 \\
\hline AS_8: I can introduce animation into slides. & 9.52 & 25.40 & 65.08 \\
\hline
\end{tabular}

Tahap penggunaan Internet dalam kalangan pelajar ditunjukkan dalam Jadual 4. Secara keseluruhannya, dapatan kajian menunjukkan pelajar mahir menggunakan internet bagi tujuan komunikasi dan pembelajaran iaitu mencari dan membawa turun bahan dari internet. Aktiviti yang agak teknikal seperti penggunaan enjin carian meta dan alatan pembangunan web didapati agak kurang popular dalam kalangan pelajar. Pelajar juga didapati kurang arif memasuki sesuatu laman web secara terus melalui alamat web berkenaan.

Jadual 4: Sumber Internet

\begin{tabular}{|l|c|c|c|}
\hline & $\begin{array}{c}\text { Rendah } \\
(\%)\end{array}$ & $\begin{array}{c}\text { Pertengahan } \\
(\%)\end{array}$ & $\begin{array}{c}\text { Tinggi } \\
(\%)\end{array}$ \\
\hline $\begin{array}{l}\text { AR_1: I can access an Internet site via its website } \\
\text { address. }\end{array}$ & 31.75 & 46.03 & 22.22 \\
\hline AR_2: I can download files from the Internet. & 0.00 & 15.87 & 84.13 \\
\hline AR_3: I can send and receive e-mail messages. & 0.00 & 4.76 & 95.24 \\
\hline AR_4: I can attach files to outgoing e-mails. & 1.59 & 15.87 & 82.54 \\
\hline AR_5: I can sort messages and file in created folders. & 4.76 & 17.46 & 77.78 \\
\hline $\begin{array}{l}\text { AR_6: I can save a document in various file formats } \\
\text { including HTML. }\end{array}$ & 7.94 & 39.68 & 52.38 \\
\hline AR_7: I can save text and images from web pages. & 4.76 & 9.52 & 85.71 \\
\hline $\begin{array}{l}\text { AR_8: I can communicate online with other students } \\
\text { on homework / assignment. }\end{array}$ & 1.59 & 7.94 & 90.48 \\
\hline
\end{tabular}




\begin{tabular}{|l|c|c|c|}
\hline AR_9: I can use web search engines very well. & 3.17 & 6.35 & 90.48 \\
\hline $\begin{array}{l}\text { AR_10: I can do deep web searching using } \\
\text { appropriate meta-search engines very well. }\end{array}$ & 34.92 & 44.44 & 20.63 \\
\hline AR_11: I can use web authoring tools. & 23.81 & 44.44 & 31.75 \\
\hline $\begin{array}{l}\text { AR_12: I can chat on the Internet using instant } \\
\text { messaging tools (Yahoo, MSN, Skype, etc.). }\end{array}$ & 3.17 & 19.05 & 77.78 \\
\hline
\end{tabular}

Penggunaan perkakasan ICT dalam kalangan pelajar juga agak baik. Seperti yang ditunjukkan dalam Jadual 5, majoriti pelajar iaitu melebihi 50\% tahu menggunakan camera digital untuk mengambil gambar, berkomunikasi melalui kamera web di internet dan membuat salinan gambar menggunakan pengimpas digital. Walau bagaimanapun, hanya segelintir sahaja pelajar (30\%) yang tahu mengendalikan Liquid Crystal Display (LCD) atau projektor Multimedia bagi tujuan persembahan multimedia.

Jadual 5: Pekakasan ICT

\begin{tabular}{|l|c|c|c|}
\hline & $\begin{array}{c}\text { Rendah } \\
(\%)\end{array}$ & $\begin{array}{c}\text { Pertengahan } \\
(\%)\end{array}$ & $\begin{array}{c}\text { Tinggi } \\
(\%)\end{array}$ \\
\hline IE_1: I can use a digital camera to capture images. & 3.17 & 20.63 & 76.19 \\
\hline $\begin{array}{l}\text { IE_2: I can use the web camera to communicate on } \\
\text { the Internet. }\end{array}$ & 9.52 & 25.40 & 65.08 \\
\hline $\begin{array}{l}\text { IE_3: can set up and use Liquid Crystal Display } \\
\text { (LCD) or Multimedia Projector. }\end{array}$ & 30.16 & 38.10 & 31.75 \\
\hline IE_4: I can use a scanner to copy images. & 6.35 & 36.51 & 57.14 \\
\hline
\end{tabular}

\section{Perbincangan dan Kesimpulan}

Secara keseluruhannya tahap literasi ICT dalam kalangan pelajar amat memuaskan. Situasi ini mungkin disebabkan oleh pelajar sering mengaplikasikan teknologi ICT dalam proses pembelajaran mereka. Implementasi seperti ini secara tidak langsung mengasah kemahiran ICT dalam kalangan pelajar. Walau bagaimanapun, aplikasi ICT yang jarang digunakan oleh pelajar dalam proses pembelajaran menunjukkan tahap penguasaan yang agak lemah. Situasi ini menunjukkan, pelajar masih perlu dibimbing dan didedahkan dengan teknologi ICT selain dari yang mereka sering gunakan.

Pihak universiti juga perlu merangka kaedah yang bersesuaian bagi mendedahkan pelajar dengan teknologi ICT terkini. Ini adalah selari dengan Aziz \& Hassan (2014) yang mengetengahkan peranan universiti sebagai penyedia pasarana ICT dan tenaga pengajar yang mahir dalam ICT. Tenaga pengajar ICT perlu sentiasa berkeyakinan, cekap dan sentiasa peka dengan perubahan terkini dalam ICT. Menurut Bingimlas (2009) faktor-faktor ini adalah antara halangan yang perlu diatasi bagi menjayakan integrasi ICT dan pengajaran.

Pendekatan amalan ICT secara terbenam dalam kurikulum sedia ada perlu dipertingkatkan dan ditambah baik. Kaedah ini secara tidak langsung akan mengalakkan pelajar meneroka teknologi ICT baharu bagi memenuhi keperluan pengajian mereka. Pendekatan pembelajaran teradun juga boleh dilaksanakan bagi membantu pelajar meningkatkan kemahiran ICT mereka (Wen et al., 2016). Kajian oleh Tsoni \& Pange (2014) menunjukkan bahawa kemahiran ICT dalam kalangan pelajar boleh ditingkatkan melalui implementasi kursus secara atas talian. Selain itu, kajian oleh Yamin \& Ishak (2017) juga menunjukkan pembelajaran teradun bukan sahaja meningkatkan kemahiran ICT tetapi juga prestasi akademik pelajar. 


\section{Penghargaan}

Terima kasih kepada Universiti Utara Malaysia yang membiayai penyelidikan ini di bawah Skim Geran Pembangunan Pelajar (Kod S/O: 13088) dan Pusat Pengurusan Penyelidikan dan Inovasi, Universiti Utara Malaysia yang menyelia penyelidikan ini.

\section{Rujukan}

Aziz, S. \& Hassan, H. (2014) Assessment of Students' Knowledge of Computer: Construction of a Test for Assessment. International Journal of Trade, Economics and Finance, 5(2), pp.187-190.

Basri, W.S., Alandejani, J.A, \& Almadani, F.M. (2018) ICT Adoption Impact on Students' Academic Performance: Evidence from Saudi Universities. Education Research International, Vol. 2018, Article ID 1240197, 9 pages, 2018. https://doi.org/10.1155/2018/1240197.

Bingimlas, K.A. (2009) Barries to the Successful Integration of ICT in Teaching and Learning of ICT in Technology and Learning Environments: A Review of the Literature. Eurasia Journal of Mathematics, Science \& Technology Education, 5(3), pp.235-245

Bonner, M. (2017). What is Industry 4.0 and What Does it Mean for My Manufacturing? Retrieved on February 25, 2018 from https://blog.viscosity.com/blog/what-is-industry4.0-and-what-does-it-mean-for-my-manufacturing

Hernandez, R.M. (2017) Impact of ICT on Education: Challenges and Perspectives. Propósitosy Representaciones, 5(1), 325-347

Hoskins \& Van Hooff (2005) Motivation and ability: which students use online learning and what influence does it have on their achievement? British Journal of Educational Technology, 36(2), 17-192

Ichniowski, C., Shaw, K., \& Prennushi, G. (1997). The Effects of Human Resource Management Practices on Productivity: A Study of Steel Finishing Lines. The American Economic Review, 87(3), 291-313

Linton, I. (2018). The Benefits of Using ICTs in Business \& Finance. Retrieved on February 25, 2019 from https://bizfluent.com/list-6641121-benefits-using-icts-businessfinance.html

MDEC (2016). MSC Malaysia Annual Industry Report 2015. Malaysia Digital Economy Corporation Sdn. Bhd.: Malaysia

Palvalin, M., Lönnqvist, A., \& Vuolle, M. (2013). Analysing the impacts of ICT on knowledge work productivity. Journal of Knowledge Management, 17(4), 545-557

Plaatjies. F., \& Mitrovic, Z. (2014). ICT and skills shortage: South African case study of retaining ICT-skilled professionals. Proceedings of the e-Skills for Knowledge Production and Innovation Conference, Cape Town,South Africa, pp. 351-369.

Ramlan, J. \& Ahmed, E.M. (2010) The Impact of ICT in Malaysia: A Simultaneous Equations Approach. World Journal of Science, Technology and Sustainable Development, 7(1), 61-72

SKMM (2016). Komunikasi dan Multimedia: Buku Maklumat Statistik Separuh Pertama 2016. Suruhanjaya Komunikasi dan Multimedia Malaysia: Malaysia

Tsoni, R. \& Pange, J. (2014) Improving ICT Skills of Students Via Online Courses. Proceedings of ICICTE 2014, pp:335-342

Tyler, L. (2005). ICT Literacy: Equipping Students to Succeed in an Information-Rich, Technology-Based Society. An Issue Paper. Educational Testing Service.

Wen, A. S., Zaid, N. M., \& Harun, J. (2016) Enhancing students' ICT problem solving skills using flipped classroom model, IEEE 8th International Conference on Engineering Education (ICEED), Kuala Lumpur, pp. 187-192. doi: 10.1109/ICEED.2016.7856069 
Yamin, F.M. \& Ishak, W.H.W. (2016) E-Skills of Undergraduate Students. Journal of Education and Social Sciences, Vol. 4, (June), pp. 314-318

Yamin, F.M. \& Ishak, W.H.W. (2017) Does the Blended Learning and Student Centered Learning Method Increase Student's Performance? Proceedings of the 1st Inspirational Scholar Symposium (ISS 2016), pp. 8-17

Yusuf, M.O. \& Balogun, M.R. (2011) Student-Teachers' Competence and Attitude towards Information and Communication Technology: A Case Study in a Nigerian University. Contemporary Educational Technology, 2(1), 18-36 